\title{
Risk of Fear and Anxiety in Utilising Health App Surveillance Due to COVID-19: Gender Differences Analysis
}

\author{
Adi Alsyouf ${ }^{1}\left(\mathbb{D}\right.$, Ra'ed Masa'deh ${ }^{2, *(\mathbb{D}}$, Moteb Albugami ${ }^{3}$, Mohammad Al-Bsheish ${ }^{4}\left(\mathbb{D}\right.$, Abdalwali Lutfi $^{5}(\mathbb{D})$ and \\ Nizar Alsubahi ${ }^{1}$
}

check for updates

Citation: Alsyouf, Adi, Ra'ed Masa'deh, Moteb Albugami, Mohammad Al-Bsheish, Abdalwali Lutfi, and Nizar Alsubahi. 2021. Risk of Fear and Anxiety in Utilising Health App Surveillance Due to COVID-19: Gender Differences Analysis. Risks 9: 179. https:// doi.org/10.3390/risks9100179

Academic Editor: Mogens Steffensen

Received: 19 August 2021

Accepted: 20 September 2021

Published: 8 October 2021

Publisher's Note: MDPI stays neutral with regard to jurisdictional claims in published maps and institutional affiliations.

Copyright: (C) 2021 by the authors Licensee MDPI, Basel, Switzerland. This article is an open access article distributed under the terms and conditions of the Creative Commons Attribution (CC BY) license (https:/ / creativecommons.org/licenses/by/ $4.0 /)$.
1 Department of Managing Health Services and Hospitals, College of Business (COB), Faculty of Business Rabigh, King Abdulaziz University, P.O. Box 344, Jeddah 21991, Saudi Arabia; oal@kau.edu.sa (A.A.); Nalsubahi@kau.edu.sa (N.A.)

2 Department of Management Information Systems, School of Business, University of Jordan, Amman 11942, Jordan

3 Department of Management Information Systems, College of Business (COB) Rabigh, King Abdulaziz University, P.O. Box 344, Jeddah 21991, Saudi Arabia; maalbugami@kau.edu.sa

4 Department of Healthcare Administration, Batterjee Medical College (BMC), P.O. Box 6231, Jeddah 21442, Saudi Arabia; mohammed.ghandour@bmc.edu.sa

5 Department of Accounting, College of Business Administration, King Faisal University, Al-Hassa 31982, Saudi Arabia; aalkhassawneh@kfu.edu.sa

* Correspondence: r.masadeh@ju.edu.jo

\begin{abstract}
Although technology trends and acceptance have been considered crucial topics, limited research has examined stress-specific factors such as health anxiety in the context of the COVID-19 pandemic based on people's attitudes toward a mobile health app using the Technology Acceptance Model (TAM). Accordingly, this study primarily highlights the psychological determinants stemming from the COVID-19 pandemic that affect the usage of a mobile health app. The study followed a crosssectional design and adopted a snowball sampling technique to collect the data. The findings showed a significant association between perceived usefulness, perceived ease of use, and event-related fear and Tabaud App intention. The relationships between Tabaud App intention and COVID19 anxiety on Tabaud App usage were also revealed. The study found a significant association between perceived ease of use and perceived usefulness. Additionally, the multi-group analysis showed that only two paths related to Tabaud App intention, perceived ease of use and perceived usefulness, differed significantly between males and females. Additionally, women experienced anxiety disorders more than men. The study contributes to the previous knowledge on the field by examining the psychological determinants resulting from the COVID-19 pandemic that influence using a mobile health app, namely, event-related fear and COVID-19 anxiety. The study results may help governments, health policymakers, and health organisations in Saudi Arabia contain the spread of the COVID-19 pandemic.
\end{abstract}

Keywords: COVID-19 pandemic; TAM; mHealth; anxiety; event-related fear; Saudi Arabia

\section{Introduction}

Studies have proven that Severe Acute Respiratory Syndrome Coronavirus 2 (SARSCoV2) caused the recent COVID-19 pandemic (Alsyouf 2020). This severe pandemic has been found to cause dangerous psychological effects such as fear of being ill, stress, anxiety, fear of dying, and stigmatisation, all of which require immediate attention (Alkhamees et al. 2020; Alsyouf 2020; Rosenbaum 2020). Research completed on similar past pandemics such as Ebola, H1N1, avian influenza, and SARS 2003 has demonstrated that psychological effects that widely emerge from pandemics produce health worries, feelings of anxiety, and safety behaviour (Jalloh et al. 2018; Lei et al. 2020; Lau et al. 2010; Ni et al. 2020). Other studies have reported that half of the population experiences anxiety during virus-induced pandemics (Ni et al. 2020; Lei et al. 2020). 
In the case of Saudi Arabia, as with several other countries, the first reported case of COVID-19 was in 2020, after which cases throughout the world increased (Alkhamees et al. 2020). Owing to such constantly increasing cases, the Ministry of Health proactively developed social media campaigns for citizens and residents to boost stay at home warnings and adherence to instructions. This was followed by the imposition of a lockdown in cities with high cases of COVID-19, including Riyadh, Mecca, and Medina, which saw the application of several movement restrictions. The last resort came in the form of a curfew imposed in all the cities of Saudi Arabia (Alkhamees et al. 2020).

Because COVID-19 cases were dreadfully alarming in many countries (Sadowski et al. 2021), people began living their daily lives with fright and shock (Alsyouf 2020). Research in this field stressed that people, particularly medical staff, experienced anxiety and depression due to quarantines (Holmes et al. 2020; Lai et al. 2020; Moreno et al. 2020). A study was conducted by Wang et al. (2020a) on Chinese people to explore the psychological effects resulting from COVID-19, which demonstrated that around half of respondents revealed medium to high levels of negative psychological impacts, in which $16.5 \%$ and $28.8 \%$ reported medium to high levels of anxiety and depression symptoms, respectively. In comparison, $8.1 \%$ revealed high levels of stress (Wang et al. 2020a).

Many Chinese people stated that they were afraid of the COVID-19 pandemic, which led them to feel anxious (Wang et al. 2020a; Wang et al. 2020b; Zhang and Ma 2020). Some researchers discussed the relationships between anxiety and different emotional symptoms and the COVID-19 (Alkhamees et al. 2020; Cao et al. 2020; Huang and Zhao 2020; Lai et al. 2020; Wang et al. 2020a; Qiu et al. 2020).

Although several models have discussed health anxiety (Brown et al. 2020; Williams 2004), research has not completely understood health anxiety. For example, factors such as amplification, vulnerability, and coping concerning health anxiety during the COVID-19 need to be investigated (Asmundson and Taylor 2020; Jungmann and Witthöft 2020; Rajkumar 2020; Zhang and Ma 2020).

Thus, the present study contributes to previous knowledge on the field by examining the psychological determinants resulting from the COVID-19 pandemic, Event-related Fear and COVID-19 anxiety, using a mobile health app. Since women experience anxiety disorders more than men (Dodd et al. 2021; McLean and Anderson 2009; McLean et al. 2011; Rzymski et al. 2021; Sun et al. 2021), the variation between men and women for anxiety disorder can be studied and analysed by exploring gender difference in mobile-health adoption through a multi-group analysis technique. Understanding gender-associated differences is important because policy responses have not often addressed the gendered impacts of disease outbreaks (Galasso et al. 2020; Smith 2019). It may be interesting to understand if the relationship between fear and anxiety in utilising Health App Surveillance may be moderated by gender.

The present study is organised into five sections; the next section presents the literature review, theoretical background, and the formulation of study hypotheses. This is followed by the Methodology section, after which the study results are presented. The final section contains the discussion and the implications of the findings to management and theory. This latter section also enumerates research limitations and future research avenues.

\section{Literature Review and Theoretical Foundation}

\section{1. mHealth}

Nowadays, evolving wireless mobile technologies such as mobile applications create various services such as $\mathrm{m}$-banking, $\mathrm{m}$-learning, $\mathrm{m}$-paying, and $\mathrm{mHealth}$ that facilitate our lives (Al-Okaily et al. 2020b, 2020c; Alkhamees et al. 2020; Al-Dmour et al. 2020; Alsyouf 2020; Rathnayake et al. 2020; Khassawneh 2014). Internet availability plays a critical role in accelerating platforms for different applications related to health informatics to provide faster health information services to consumers. Technology has a key role in improving the health of populations all over the world. With its reasonable price and accessibility, 
smartphone technology may be the next best technology to achieve such a challenging health enhancement feat (Alsyouf 2020; Mayes et al. 2016).

Alsyouf (2020) gathered statistical information concerning the proliferation of smartphones in developing countries, particularly in the Middle East and Africa (MEA) region. He found that in a span of just a few years (2016-2020), smartphones numbering in the billions were sold in China (713 million), India (340 million), Brazil (136.46 million), and Indonesia (81.87 million). Aside from this, other developing nations had governments offering tax exemptions to citizens to purchase smartphones (e.g., Malaysia and Ghana). In particular, the MEA region noted a considerable increase in smartphone users due to its benefits. For instance, towards the end of 2019, the number of smartphone users in Saudi Arabia went over the 20 million marks, and almost half of the country's citizens are expected to own and use smartphones owing to the e-government and e-commerce services that have contributed to the increasing demand for using smartphones.

People make use of smartphones for different healthcare purposes; some for personalising healthcare, specifically to monitor the status of a disease or make medical appointments, while others make use of it in different ways. Regardless of the purposes behind its usage, smartphones technology in healthcare has been shown to provide multiple advantages to users worldwide. Smartphone technology has a massive contribution to healthcare and all medical fields (Alsyouf 2020). Moreover, it enhances international interactions, improves care, and reduces healthcare costs (Alsyouf 2020; Mayes et al. 2016). Smartphone technologies have been found to solve challenging health-related scenarios that existed in the past (Alsyouf 2020). For example, during the Ebola outbreak in West Africa in 2013, authorities used the technologies to track mobile phones to collect information, which helped them take suitable decisions such as isolating high-risk areas and enabling the authorities to channel resources

Based on the data reviewed above, smartphone technologies may provide solutions for global health and help in the current COVID-19 pandemic surveillance worldwide. The "Tabaud" Application was one of the technological solutions developed to monitor and track the spread of Coronavirus in Saudi Arabia. This technology informs people whether they have contacted infected people during the past fourteen days by sending users notifications (Alsyouf 2020; Ministry of Health 2020). Two international companies (Google and Apple) maintained policies assuring a user's full privacy (Saudi Data and Artificial Intelligence Authority 2020). This application is available for all people to easily download and use to achieve health and safety purposes (Alsyouf 2020). The application allows users to receive proactive notes if any registered infected person has been detected and enables people to directly contact the Ministry of Health in Saudi Arabia (Saudi Data and Artificial Intelligence Authority 2020).

Few studies have investigated the relative "event-related fear" as a variable and anxiety sensitivity to COVID-19 using the Technology Acceptance Theory (TAM) in Saudi Arabia. Accordingly, the present study fills this knowledge gap, examining the psychological determinants that emerged from the COVID-19 that influence using the mobile health app, "Tabaud".

\subsection{Theoretical Model}

\subsubsection{Technology Acceptance Model (TAM)}

TAM is an influential model that explains technology usage behaviour (Al-Okaily et al. 2020a; Alsyouf and Ishak 2018; Al-Syouf 2017). TAM claims that an individual technology usage behaviour (or behavioural desire to accept the technology) can be measured through an individual's technology usage attitude. Two main predictors have emerged from the attitude toward usage: perceived ease of use and perceived usefulness (Al-Okaily et al. 2020b). Perceived usefulness is how individuals believe that using technology can foster their task performance, while perceived ease of use refers to how easy individuals think using technology is (Davis et al. 1989). Moreover, perceived ease of use indirectly affects attitudes related to perceived usefulness. 
TAM models have revealed their ability to explain the differences between technology usage and behaviour across different contexts (Al-Okaily et al. 2020c; Baptista and Oliveira 2016; Chen et al. 2019; Dawson et al. 2017).

Even though these models have been broadly examined and proved their validity in the field of health information systems utilised by medical staff, they rarely examined the modelling of consumers' acceptance of health information applications (Tao et al. 2018, 2020a, 2020b; Hsu and Wu 2017). Research has found that the way consumers accept the health informatics applications may be dissimilar from that of professionals because consumers may not have enough self-efficacy and or experience in usage, which make them more likely to face difficulties in applying health informatics application (Alsyouf 2021; Hwang et al. 2016; Tao et al. 2020a). Therefore, finding ways that help customers' acceptance is needed.

Even though TAM is popular, several researchers have observed that the TAM model has a critical weakness because another factor can determine a person's attitude. This factor is social influence. It has been found that a person's attitude towards information technology usage can be measured through social influence (Mathieson et al. 2001; Venkatesh and Davis 2000). David's TAM model examined internal motivations while neglecting external motivations. The model concentrated on the outcomes of using IT, meaning that process usage itself has not been discussed yet. In short, extending the TAM model with external factors using the conceptual model itself is highly recommended to expand new variables to the TAM model. In this instance, three external factors were added to the TAM model: health anxiety sensitivity to COVID-19 and event-related fear and gender as a moderator to determine Saudi citizens' Tabaud App usage, as illustrated in Figure 1.

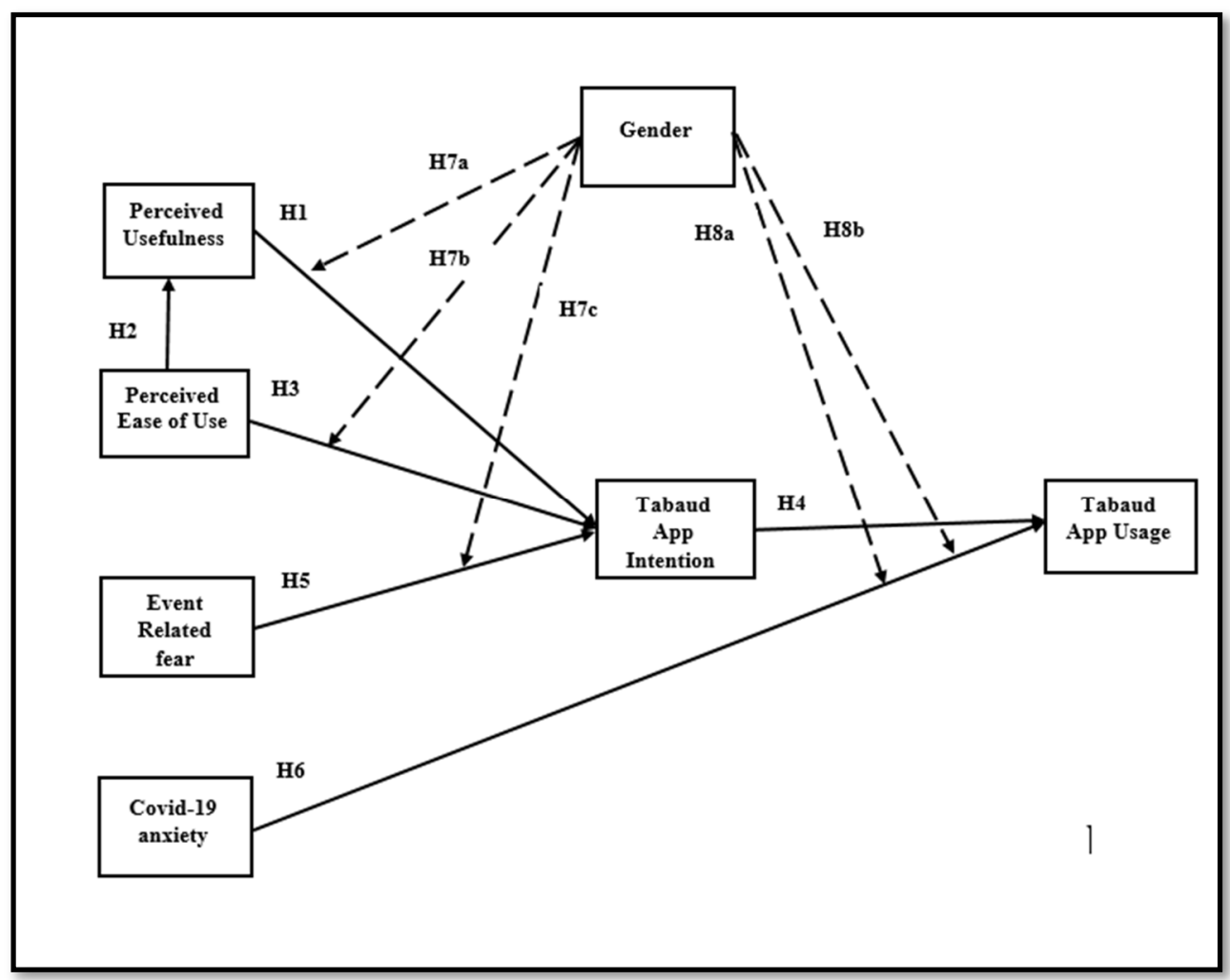

Figure 1. The research framework.

\subsubsection{Proposed Model and Hypothesis Formulation}

Prior studies and theoretical discussions were the basis for extending TAM in the present study by adding psychological determinants stemming from the COVID-19 pandemic, affecting mobile health app use. Specifically, three external factors were included in 
the TAM model: health anxiety sensitivity to COVID-19, event-related fear, with gender as a moderating variable to determine the Tabaud App usage among Saudi citizens. The study's variables include Tabaud App usage as the dependent variable, health anxiety sensitivity to COVID-19, event-related fear, gender, perceived usefulness, and perceived use as the independent variables. Figure 1 is a graphical representation of the corresponding hypotheses.

Perceived Usefulness (PU)

PU is referred to in this study as the level to which an individual's trusts that accepting/using a certain system/technology will improve their performance on the job (Davis 1989). Related studies indicated the significant influence of PU on intention to use the system. According to Zhang et al. (2017), there is a positive association between PU and intention to use mHealth type, while Binyamin and Zafar (2021) revealed that PU has a constructive influence on the intention towards mHealth types of usage. Thus, the present study proposes the following hypothesis for testing:

Hypothesis 1 (H1). The PU of the Tabaud App positively influences the intention of its use.

Perceived Ease of Use (PEU)

PEU is the level to which an individual believes that the use of a certain system/ technology will be easy with low effort (Davis 1989). Juxtaposed to the purpose of this study, PEU is the user's belief that using the mHealth system is both mentally and physically free of effort. In past studies, the association between PU and intention to use was supported; for instance, Binyamin and Zafar (2021) found that PEOU has a significant influence over PU when it comes to mHealth, while Tsai et al. (2020) and Li et al. (2019) found the positive influence of PEOU on the intention towards using an mHealth App. Thus, this research proposes the following corresponding hypotheses for testing:

Hypothesis 2 (H2). The PEU of the Tabaud App positively influences its PU.

Hypothesis 3 (H3). The PEU of the Tabaud App positively influences the intention of its use.

Intention to Use

In the field of user acceptance of new technologies, intention to use is a top determinant, and more importantly, the behavioural intention concept is defined as the plan of the individual to perform a certain behaviour (Fishbein and Ajzen 1977). Regarding mHealth use, intention to use the system refers to the plan to use mHealth technology. In this background, Binyamin and Zafar (2021) supported the significant influence of intention use on the use of an mHealth App. Similarly, Alam et al. (2020) and Kissi et al. (2020) determined whether the intention to use an mHealth App positively affected its usage. Based on the above-discussed findings, this study proposes the following hypothesis for testing.

Hypothesis 4 (H4). The intention to use the Tabaud App positively influences its actual use.

Furthermore, this study examines Saudi citizens' acceptance of using the Tabaud App from the user's perspective by integrating event-related fear and health anxiety sensitivity to COVID-19 with TAM.

\subsubsection{Health Anxiety Sensitivity to COVID-19 and Event-Related Fear}

Health anxiety emerging from pandemics can remarkably impact people (avoidance, stress, and thoughts relating to negative intrusive). These effects can be associated with unfavourable or ineffective preventative behaviours (Gaygisiz et al. 2012; Wang et al. 2020a; Qiu et al. 2020). 
People's perceptions of health anxiety related to pandemics are various (Gaygisiz et al. 2012). Thus, studying factors that influence health anxiety related to pandemics may contribute to an in-depth understanding of user's adoption of health applications in pandemics. The COVID-2019 pandemic has been found to provoke feelings of sickness, fear, death, helplessness, and stigma, but conducting studies may help understand mental health status, which is needed to help people (Alkhamees et al. 2020).

Since people are unaware of probabilities and numbers, they will be unable to assess the level of risk by calculating the probability and assessing the consequences for all options (Loewenstein et al. 2001). Thus, they generally depend on intuition and innate feelings to judge event risks, which is called an intuition-based mechanism with evolutionary significance (Fessler et al. 2004; Slovic et al. 2004). As a risk sometimes happens quickly, intuition may assist people to swiftly leave complicated and dangerous environments. It has been claimed that emotions cause such intuitive risk assessment, which is defined as the "risk as feelings" hypothesis (Slovic et al. 2004). To be more precise, people's judgments about event danger rely on the emotional feelings at a certain time, not on the real probability of severity.

Fear and anxiety are two emotional feelings significantly correlated with risks and causes of emergencies (Fan et al. 2011). Several studies have revealed that people's fear and anxiety rapidly increased after public health emergencies such as what happened with Zika and H1N1 outbreaks (Tausczik et al. 2012; Yang et al. 2018). Two negative valence emotions probably provoke a pessimistic risk evaluation (Finucane et al. 2000; Wright and Bower 1992). For example, Johnson and Tversky's study (Johnson and Tversky 1983) revealed that people either underestimate or overestimate the number of deaths due to floods or smoking after reading newspapers. Similarly, this study investigates the specific effects of emotions beyond valence on users' acceptance of innovation, specifically health application usage, which assists in COVID-19 pandemic surveillance and contamination.

Fear can provoke individuals' risk estimates of adverse events such as strokes (Lerner and Keltner 2000) and their perception of future terrorist attacks (Lerner et al. 2003). Hence, when individuals face or are directly exposed to a risk event, they are more likely to experience anxiety with higher acceptance of innovation. Based on that, the following hypotheses are posited:

Hypothesis 5 (H5). Event-related fear will influence Tabaud App intention positively.

Hypothesis 6 (H6). COVID-19 anxiety will influence Tabaud App usage positively.

\subsubsection{The Moderating Effect of Gender as a Multi-Group Analysis}

The assumption that all study samples are drawn from homogeneous populations may lead to incorrect conclusions. Therefore, researchers must routinely assess heterogeneity effects (i.e., size of firms, country, age, gender, income) through MGA (Cheah et al. 2020; Lutfi et al. 2020). This current study investigated if gender moderates the association between Tabaud App usage and its determinants (event-related fear, PEU, PU and COVID19 anxiety).

Literature on gender differences reports that males have intendancies to be highly taskoriented (Minton and Schneider 1980). Hence, males' performance expectations, which emphasise task achievement, are probably especially salient. The theory of Gender schema claims that these variances emerged from the roles of gender and socialisation processes enhance from early ages instead of biological gender (Venkatesh et al. 2003). Previous works outside the IT/IS context have argued that gender differences play a critical role in making a strong psychological base and are relatively changeable over time (Kirchmeyer 2002).

Studies report that women have higher fears and are more likely to develop anxiety disorders than men. Women's higher vulnerability for anxiety disorders can be relatively understood by investigating gender variances in the etiological factors known to contribute to anxiety (McLean and Anderson 2009). A recent work conducted by Liu et al. (2020) about the prevalence of Posttraumatic Stress Symptoms (PTSS) in China during the spread 
of COVID-19 showed that women exhibited remarkably higher PTSS in the domains of re-experiencing, hyper-arousal, and negative alterations in cognition or mood.

Similarly, Teng et al. (2020) studied the fatigue and psychological status of Chinese frontline staff. Their study revealed that women experience more extreme symptoms such as anxiety and depression. The study supported past studies that severe mental disorders are more common among women after disturbing events than men (McLean and Anderson 2009; Kendler et al. 2001).

Furthermore, Sun et al. (2021) conducted a study investigating psychiatric symptoms (anxiety, traumatic stress, and depression) during state-enforced quarantine among students in Chinese universities revealed that female students reported greater anxiety levels than men. In a study exploring the psychological wellbeing of domestic and international students during the COVID-19 pandemic in Australian universities, Dodd et al. (2021) found that females were more impacted in their studies than men. In addition, Rzymski et al. (2021), in a study of the perceptions and attitudes of Polish citizens toward COVID-19 vaccines, revealed that females with a lower level of education and those not seeking any information on the COVID-19 vaccines had a higher fear of vaccination. Therefore, this current study proposes that women will tend to be keener than men to use the Tabaud App. Thus, this current study posited:

Hypothesis $\mathbf{7}(\mathbf{H 7} \mathbf{a}, \mathbf{b}, \mathbf{c})$. The strength of the determinants of Tabaud App intention (event-related fear, PEU and PU) differ between women and men such that the strength of the relationship will be more significant for women.

Hypothesis $\mathbf{8} \mathbf{~ ( H 8 a , b ) . ~ T h e ~ s t r e n g t h ~ o f ~ t h e ~ d e t e r m i n a n t s ~ o f ~ T a b a u d ~ A p p ~ u s a g e ~ ( C O V I D - 1 9 ~ a n x i e t y ~}$ and Tabaud App intention) differ between women and men such that the strength of the relationship will be more significant for women.

\section{Research Method}

\subsection{Study Design}

A cross-sectional design was employed in this study to investigate external factors in the TAM model, namely, health anxiety sensitivity to COVID-19, event-related fear, and gender as a moderator that is claimed to determine Saudi citizens' Tabaud App usage during the COVID-19 pandemic, specifically during the curfew in the Kingdom of Saudi Arabia (KSA). An online-based survey questionnaire was sent through social media websites and applications. Participants received the questionnaire to be answered through WhatsApp's groups via a non-probabilistic snowball sampling technique for respondents recruitment because social distancing is a critical matter during this pandemic outbreak (Roy et al. 2020; Shi et al. 2020a, 2020b). Regarding "Twitter," tweets or messages using diverse accounts in KSA were posted. Each questionnaire had information on the first page, including the title, the study purpose, and the time estimated to fill the questionnaire. After the consent, participants clicked "start the survey" and answered the questions.

\subsection{Study Procedure}

Due to the curfew imposed by the Saudi authorities, an online data collection technique, which is Google forms, was used. Data were collected using an online e-questionnaire that was distributed via smartphones, tablets and PCs. Data confidentiality was taken into consideration. Data collection lasted from 11 November to 11 December 2020. The sample size was calculated using Krejcie and Morgan's 1970 table. The study sample size criterion established by Krejcie and Morgan (1970) indicated that 384 was a suitable size for generalising findings. The number of responses was 738 .

\subsection{Data Instrument}

All constructs and items were drawn from prior studies to ensure convergent and discriminant validity. Perceived usefulness and perceived ease of use were the first two 
variables. Each was tested utilising four points adapted from Davis's scale (1989) and Taylor and Todd's scale (1995). The third one was COVID-19 anxiety, which used nine items adapted from Wheaton et al. (2012). Meanwhile, event-related fear was measured through three items adapted from Boudreaux et al. (2010). Finally, intention to use and usage were measured using three items adapted from Venkatesh et al. (2012) and Alsyouf and Ishak (2018).

The entire list of items is listed in Appendix A. The survey instrument was translated from English into Arabic according to Brislin's guidelines (1986). Seven academic representatives' experts in information technology were interviewed in the pretest study. Some changes were made to improve the questionnaire. A 5-point Likert-type scale with responses ranging from "strongly disagree" to "strongly agree" was utilised to evaluate the measurements.

\section{Data Analysis}

Partial Least Squares (PLS) was employed to evaluate the suggested framework. A Structural Equation Modelling (SEM) approach can also enable PLS to simultaneously examine the measurement and structural models (Alshira'h et al. 2020a; Gefen et al. 2011; Lutfi 2020). Moreover, PLS can be applied for complicated models, which have a hierarchical structure, many indicators, relationships, and constructs (Alshira'h et al. 2020b; Chin 2010; Lutfi et al. 2016). Additionally, PLS resolves problems regarding small sample size and error terms and have fewer strict assumptions of normality distribution (Alshirah et al. 2021; Chin 2010; Lutfi et al. 2017; Sarstedt et al. 2014). PLS version 3.0 M3 was used to evaluate the model proposed.

Table 1 presents the respondents' demographic characteristics, such as gender, age, residence location, and education level. The PLS analysis process's first step is to conduct the measurement model's reliability and validity tests. The reflective measurement models are assessed according to convergent validity (average variance extracted), indicator reliability, internal consistency, and discriminant validity.

Table 1. Demographic characteristics of the respondents.

\begin{tabular}{cccc}
\hline Item & Category & $\mathbf{N}$ & $\%$ \\
\hline \multirow{3}{*}{ Gender } & Male & 410 & 55.6 \\
& Female & 328 & 44.4 \\
& Total & 738 & 100 \\
\hline \multirow{2}{*}{ Age } & 17 years old and younger & 9 & 1.2 \\
& $18-34$ years old & 423 & 57.3 \\
& 35-44 years old & 111 & 15 \\
& $45-54$ years old & 82 & 11.1 \\
& $55-64$ years old & 82 & 11.1 \\
& 65 years and over & 31 & 4.2 \\
& Total & 738 & 100 \\
\hline \multirow{2}{*}{ Education level } & High school degree and below & 145 & 19.6 \\
& Diploma certificate & 37 & 5 \\
& Bachelor's degree & 418 & 56.6 \\
& Master's degree & 85 & 11.5 \\
& PhD holders & 53 & 7.2 \\
& Total & 738 & 100 \\
\hline \multirow{2}{*}{ Province } & Western province & 483 & 65.4 \\
& Eastern province & 93 & 12.6 \\
& Southern province & 22 & 3 \\
& Northern province & 68 & 9.2 \\
& Middle province & 72 & 9.8 \\
& Total & 738 & 100 \\
\hline
\end{tabular}


Table 2 shows Cronbach's alphas (CA), Composite Reliability (CR), Item Loadings, and Average Variance Extracted (AVE) of all constructs. The results of CA and CR were found to be more than the threshold value of 0.70 for all constructs, referring to the internal consistency and the constructs appropriateness (Hair et al. 2011, 2014). 0.40. All factors were higher than 0.40 ; thus, the reliability indicator was accepted.

Table 2. Item Loading, Cronbach's alpha, Composite Reliability, Average Variance Extracted.

\begin{tabular}{|c|c|c|c|c|c|}
\hline Construct & $\begin{array}{l}\text { Measurement } \\
\text { Items }\end{array}$ & Loadings & $\begin{array}{c}\text { Cronbach's } \\
\text { Alpha }\end{array}$ & $\begin{array}{c}\text { Composite } \\
\text { Reliability } \\
\text { (CR) }\end{array}$ & $\begin{array}{c}\text { Average } \\
\text { Variance } \\
\text { Extracted (AVE) }\end{array}$ \\
\hline $\begin{array}{c}\text { COVID-19 } \\
\text { Anxiety (CA) }\end{array}$ & $\begin{array}{l}\text { CA1 } \\
\text { CA7 } \\
\text { CA8 } \\
\text { CA9 }\end{array}$ & $\begin{array}{l}0.71 \\
0.83 \\
0.64 \\
0.70\end{array}$ & 0.70 & 0.81 & 0.52 \\
\hline $\begin{array}{c}\text { Event- } \\
\text { Related Fear } \\
\text { (ERF) }\end{array}$ & $\begin{array}{l}\text { ERF1 } \\
\text { ERF2 } \\
\text { ERF3 }\end{array}$ & $\begin{array}{l}0.93 \\
0.93 \\
0.91\end{array}$ & 0.92 & 0.95 & 0.86 \\
\hline $\begin{array}{l}\text { Perceived } \\
\text { Ease of Use } \\
\text { (PEOU) }\end{array}$ & $\begin{array}{l}\text { PEOU1 } \\
\text { PEOU2 } \\
\text { PEOU3 } \\
\text { PEOU4 }\end{array}$ & $\begin{array}{l}0.90 \\
0.89 \\
0.87 \\
0.77\end{array}$ & 0.88 & 0.92 & 0.74 \\
\hline $\begin{array}{l}\text { Perceived } \\
\text { Usefulness } \\
\text { (PU) }\end{array}$ & $\begin{array}{l}\text { PU1 } \\
\text { PU2 } \\
\text { PU3 } \\
\text { PU4 }\end{array}$ & $\begin{array}{l}0.92 \\
0.94 \\
0.92 \\
0.91\end{array}$ & 0.94 & 0.96 & 0.85 \\
\hline $\begin{array}{l}\text { Tabaud App } \\
\text { Intention } \\
\text { (TAI) }\end{array}$ & $\begin{array}{l}\text { TAI1 } \\
\text { TAI2 } \\
\text { TAI3 }\end{array}$ & $\begin{array}{l}0.95 \\
0.91 \\
0.95\end{array}$ & 0.93 & 0.95 & 0.87 \\
\hline $\begin{array}{l}\text { Tabaud App } \\
\text { Usage (TAU) }\end{array}$ & $\begin{array}{l}\text { TAU1 } \\
\text { TAU2 } \\
\text { TAU3 }\end{array}$ & $\begin{array}{l}0.88 \\
0.95 \\
0.93\end{array}$ & 0.91 & 0.94 & 0.84 \\
\hline
\end{tabular}

The results also revealed that the convergent validity of all AVE constructs was higher than 0.5 , which is the conventional cut-off value. Similarly, the AVE square roots of all constructs were counted to evaluate the discriminant validity. The square roots of AVE scores were higher than the other constructs correlations, so discriminant validity was achieved (refer to Table 3 for results), with all the values being acceptable.

Table 3. Discriminant validity of the constructs.

\begin{tabular}{ccccccc}
\hline & CA & ERF & PEOU & PU & TAI & TAU \\
\hline CA & $\mathbf{0 . 7 2}$ & & & & & \\
ERF & 0.60 & $\mathbf{0 . 9 2}$ & & & & \\
PEOU & 0.18 & 0.10 & $\mathbf{0 . 8 6}$ & & & \\
PU & 0.22 & 0.17 & 0.67 & $\mathbf{0 . 9 2}$ & & \\
TAI & 0.25 & 0.17 & 0.64 & 0.60 & $\mathbf{0 . 9 4}$ & \\
TAU & 0.23 & 0.18 & 0.50 & 0.45 & 0.64 & $\mathbf{0 . 9 2}$ \\
\hline
\end{tabular}

Note: CA: COVID-19 anxiety, ERF: event-related fear. PEOU: perceived ease of use. PU: perceived usefulness. TAI: Tabaud App intention, and TAU: Tabaud App usage.

The main effect of the model was investigated to examine the hypotheses proposed to assess the structural model. A PLS path algorithm generating the path coefficients was run first to evaluate the significance of the study. This process was completed by the structural model. This model used the bootstrap procedure through generating 5000 resample (Hair et al. 2011, 2014; Lutfi 2020; Sarstedt et al. 2014). After that, PLS Multi-Group 
Analysis (MGA) was performed to examine the gender-moderating effect on the model and PLS-SEM.

Based on the study hypotheses shown in Table 4, COVID-19 anxiety was significant $(\beta=0.08, t=2.69, p<0.01)$ and affected Tabaud App usage. Hence, $\mathrm{H} 1$ is supported. At the same time, event-related fear also was significant $(\beta=0.08, t=2.60, p<0.01)$ and affected the intention to use the Tabaud App. Hence, H2 is supported.

Table 4. The assessment of structural model.

\begin{tabular}{ccccccccc}
\hline No. & Hypothesis & Beta & $\begin{array}{c}\text { Sample } \\
\text { Mean (M) }\end{array}$ & $\begin{array}{c}\text { Standard Deviation } \\
\text { (STDEV) }\end{array}$ & $\boldsymbol{t}$-Statistics & $\boldsymbol{p}$-Value & Sig. & Decision \\
\hline 1 & PU -> TAI & 0.29 & 0.29 & 0.05 & 5.58 & 0.00 & Sig. & Supported $* * *$ \\
2 & PEOU -> PU & 0.67 & 0.67 & 0.03 & 26.02 & 0.00 & Sig. & Supported \\
$3 * *$ \\
3 & PEOU -> TAI & 0.43 & 0.43 & 0.05 & 8.57 & 0.00 & Sig. & Supported $* * *$ \\
4 & TAI -> TAU & 0.62 & 0.62 & 0.03 & 20.88 & 0.00 & Sig. & Supported $* * *$ \\
5 & ERF -> TAI & 0.08 & 0.08 & 0.03 & 2.60 & 0.01 & Sig. & Supported $* * *$ \\
6 & CA -> TAU & 0.08 & 0.08 & 0.03 & 2.69 & 0.00 & Sig. & Supported \\
\hline
\end{tabular}

Note: $t$-values $>1.645^{*}(p<0.05)$; $t$-values $>1.96^{* *}(p<0.02)$; and $t$-values $>2.33^{* * *}(p<0.01)$; 1-tailed test.

Additionally, PEU was significant $(\beta=0.67, t=26.02, p<0.01)$ and affected perceived usefulness. As a result, H 3 is supported. Additionally, PEU was significant $(\beta=0.43$, $t=8.57, p<0.01)$ and affected Tabaud App intention. Accordingly, $\mathrm{H} 4$ is advocated. Moreover, PU was significant $(\beta=0.29, t=5.58, p<0.01)$ and affected Tabaud App intention. As a result, H 5 is supported. Furthermore, Tabaud App intention was significant $(\beta=0.62$, $t=20.88, p<0.01)$. Thus, H6 is supported.

An MGA was conducted in SEM to test how those models could be differentiated from each other (Hair et al. 2010; Hair et al. 2013). At the same time, MGA can be a comparative process for PLS that estimates across subpopulations in PLS-SEM (Hair et al. 2013; Henseler and Fassott 2010; Henseler 2012). Hence, the core goal is to check that a certain model is different or similar for these groups.

A group comparisons approach is used by the moderation effect when either an independent and moderator variable should not be a latent variable of continuation (Henseler and Fassott 2010). Studies have stressed that a variable of categorical moderator latent should be utilised as a variable of grouping that needs transformation through the dichotomisation technique, whether low or high (Hair et al. 2014; Venkatesh et al. 2011).

The present study posted gender as a demographic variable to moderate the relationships between Tabaud Application, event-related fear, perceived usefulness, and perceived ease of use. In addition, it was posited to moderate the relationships between Tabaud Application usage, Tabaud Application intention, and COVID-19. Accordingly, for statistical considerations relating to multi-group analysis, gender was divided into male and female groups.

The data were specified based on recommendations taken from Byrne (2010) and Hair et al. (2013), and male and female respondents were classified according to separate datasets. The study had data on 410 male respondents and 328 female respondents. Using MGA with $p$-statistics, each path in the structural model of males was compared with the corresponding path coefficient of females (Keil et al. 2000) (see Tables 5 and 6).

Only two paths were statistically different between the two subgroups. The first one was from perceived ease of use to Tabaud App Iitention $(p<0.01)$. The result reveals that the relationship between perceived ease of use and Tabaud App intention was more significant for females than males. The second was from perceived usefulness to Tabaud App intention $(p<0.02)$. This result indicates that perceived usefulness and Tabaud App intention's relationship was more significant for females than males. 
Table 5. Bootstrapping outcomes.

\begin{tabular}{ccccc}
\hline & $\begin{array}{c}\text { Path Coefficients } \\
\text { Original (Male) }\end{array}$ & $\begin{array}{c}\text { Path Coefficients } \\
\text { Original (Female) }\end{array}$ & $\begin{array}{c}p \text {-Value } \\
\text { (Male) }\end{array}$ & $\begin{array}{c}p \text {-Value } \\
\text { (Female) }\end{array}$ \\
\hline CA -> TAU & 0.083 & 0.094 & 0.013 & 0.014 \\
ERF -> TAI & 0.039 & 0.104 & 0.164 & 0.008 \\
PEOU -> PU & 0.69 & 0.655 & 0 & 0 \\
PEOU -> TAI & 0.307 & 0.568 & 0 & 0 \\
PU -> TAI & 0.403 & 0.181 & 0 & 0.003 \\
TAI -> TAU & 0.617 & 0.629 & 0 & 0 \\
\hline
\end{tabular}

Note: CA: COVID-19 anxiety, ERF: event-related fear, PEOU: perceived ease of use, PU: perceived usefulness TAI: Tabaud App intention, and TAU: Tabaud App usage.

Table 6. Parametric test.

\begin{tabular}{ccccc}
\hline & $\begin{array}{c}\text { Path } \\
\text { Coefficients-Diff } \\
\text { (Male-Female) }\end{array}$ & $\begin{array}{c}\text { t-Value (Male } \\
\text { vs. Female) }\end{array}$ & $\begin{array}{c}p \text {-Value (Male } \\
\text { vs. Female) }\end{array}$ & Decision \\
\hline CA -> TAU & -0.011 & 0.196 & 0.422 & Not Supported \\
ERF -> TAI & -0.065 & 1.103 & 0.135 & Not Supported \\
PEOU -> PU & 0.035 & 0.665 & 0.253 & Not Supported \\
PEOU -> TAI & -0.261 & 2.74 & 0.003 & Supported $^{* * *}$ \\
PU -> TAI & 0.223 & 2.21 & 0.014 & Supported $^{* *}$ \\
TAI -> TAU & -0.012 & 0.206 & 0.418 & Not Supported \\
\hline
\end{tabular}

Note: CA: COVID-19 anxiety, ERF: event-related fear, PEOU: perceived ease of use, PU: perceived usefulness, TAI: Tabaud App intention, and TAU: Tabaud App usage. Note: $t$-values $>1.645^{*}(p<0.05)$; $t$-values $>1.96$ ** $(p<0.02)$; and $t$-values $>2.33^{* * *}(p<0.01) ; 1$-tailed test.

\section{Discussion and Conclusions}

TAM extension has been found to be a beneficial model for predicting mhealth app usage for tracking down people who have recently been contacted with a positive COVID19 case and thus helping to break the chain of infection. Not only have the hypotheses of the original TAM model been met, but the model with the added variables has a higher predictive power. Interestingly, the study's model explained $0.418,0.460$, and 0.453 of the variance of Tabaud App usage, Tabaud App intention, and perceived usefulness, respectively.

Little attention has been paid to the effect of specific psychological determinants resulting from the COVID-19 pandemic on users' acceptance of innovation, specifically health app usage, which assists in COVID-19 pandemic surveillance and contamination from consumers' perspectives. The present study's research questions attempted to fill the gap by examining the acceptance of the Tabaud App from the perspective of Saudi citizens, integrating event-related fear and health anxiety sensitivity to COVID-19 with TAM variables. It evaluated if they were significant antecedents of citizens' Tabaud App usage or not. The results demonstrate that all hypothesised relationships were supported.

This research confirmed that perceived usefulness (H1) was a significant predictor of Tabaud App intention $(p<0.00)$. The finding is similar to previous studies in the mHealth context, which have reported PU as a major essential factor contributing to users' behavioral intention to utilise mHealth types (Binyamin and Zafar 2021; Sezgin et al. 2018; Zhang et al. 2017). This study concludes that if the citizens perceive that the Tabaud App was useful in protecting them from COVID-19 infection, they will use it more extensively.

This study also examined the relationship between perceived ease of use and perceived usefulness $(\mathrm{H} 2)$. It confirmed a significant association $(p<0.00)$ between these two constructs. The finding aligns with other studies in the mHealth context (Binyamin and Zafar 2021; Li et al. 2019; Tsai et al. 2020). The present finding proposes that perceiving that Tabaud App as an easy application may indicate that it is useful. Citizens who find the Tabaud App easy to use exert more effort to use it, which, in turn, strengthens their 
perception of its importance. An easy-to-use Tabaud App saves citizens time, and they utilise the Tabaud App more effectively.

Furthermore, the findings demonstrated a significant association between PEU and Tabaud App intention $(p<0.00)(\mathrm{H} 3)$. This finding agrees with previous studies in the mHealth context (Binyamin and Zafar 2021; Deng et al. 2018; Zhu et al. 2018). This finding implies that, without obvious perceived ease of use (PEOU), citizens' barriers to using the Tabaud App are reduced, which affects their actual use of the Tabaud App. One plausible justification for this is that mHealth is associated with new technologies. Thus, PEU is essential for citizens to use mHealth apps. Previous research study has examined the way consumers accept health informatics applications and found they may be different from health professionals' way (Hwang et al. 2016; Tao et al. 2020a) due to consumers lack of self-efficacy and negative feelings regarding usability, which make consumers more likely to encounter challenges in using health informatics applications. Therefore, finding ways to help customer acceptance is necessary.

Tabaud App intention's effect was assumed to be a strong indicator of Tabaud App usage (H4). The results indicate that the Tabaud App intention positively influenced $(p<0.00)$ Tabaud App usage. Prior research revealed a positive association between the two factors (Alam et al. 2020; Binyamin and Zafar 2021; Kissi et al. 2020). This result implies that behavioural intention is an essential indicator for users' acceptance of the new technologies. In the context of mHealth usage, behavioural intention can be a good indicator for using mHealth technology. They confirmed the notion that citizens' intention to use the Tabaud App is a crucial predictor of their actual Tabaud App usage.

The insertion of event-related fear as an independent variable provides a new perspective for studying psychological antecedents' effect on information system acceptance research in healthcare. Findings confirm a significant and positive association $(p<0.01)$ between event-related fear and Tabaud App intention (H5). This result implies that the more fear the citizens experienced of becoming infected due to the COVID-19 pandemic, the more likely they were to endorse stronger intentions to use the Tabaud App.

Finally, the findings demonstrate a significant association $(p<0.00)$ between COVID-19 anxiety and Tabaud App usage (H6). This result implies that those who experience anxiety are more likely to accept the Tabaud App when people are exposed to a risk event. Indeed, COVID-19 was described as a strongly spreading virus; thus, people with pre-existing concerns about contamination might be vulnerable to be worried about contracting sources of this disease.

The multi-group comparison analysis was assessed to investigate the stipulated hypotheses. However, only two paths differed significantly between the two subgroups. The two paths were from perceived ease of use and perceived usefulness to Tabaud App intention. The effect of perceived ease of use and perceived usefulness on Tabaud App intention was more significant for women than men. Previous studies of gender differences in other fields (Grogan et al. 1997; Konrad et al. 2000; Yuen and Ma 2002) and the results of studies of gender differences in information technology (Venkatesh and Morris 2000; Venkatesh et al. 2000) support the gender differences found for the prediction of the Tabaud App observed here. This supposes that the impact of PEU and PU on Tabaud App intention was higher among women than men for Saudi citizens.

One plausible explanation concerning mobile health app surveillance was that women exhibit more concern than men. McLean and Anderson's (2009) research show that women report greater fear and are more likely to develop anxiety disorders than men. This might reflect a higher motivation of women for using health app surveillance. Thus, using the Tabaud App, which is simple to use, is more critical for women than men. Consequently, women discover that the Tabaud App is useful for protecting them from the COVID-19 pandemic and is easy to use. The Tabaud App helps identify infected people and contacts, and proactive notes are revied when any registered infected person has been detected to request health support from the Ministry of Health. This helps reduce stress and anxiety for women. Another explanation is that women believe that utilising the app protects them 
and makes them safer; therefore, the relationship of perceived usefulness and Tabaud App intention was more significant for women than men.

\subsection{Managerial and Theoretical Implications}

The study findings have significant managerial implications. Along with the importance of safety compliance behaviours, among which are social distancing, mask-wearing, and hygiene, which constitute a major concern for the government with regard to the public (Al-Bsheish et al. 2021), the mHealth App offers solutions in light of COVID-19 surveillance by the government through electronic input, transmission, and retrieval of data from local and distant sites. Consequently, this will lead to detecting and reporting any potential pandemic. Smartphone communication technologies have become essential in all fields, and healthcare policymakers across the globe can employ mHealth as a new way to mitigate global health crises. MHealth can radically improve healthcare services even in the most remote and low-resource environments.

The COVID-19 pandemic provides an excellent opportunity to test, extend, and integrate technology acceptance models theoretically. These extensive replications, applications, and extensions/integrations of TAM have been valuable in expanding our understanding of technology adoption and extending the theory's theoretical boundaries. This study examined TAM to investigate Tabaud App usage for Saudi citizens. Moreover, the study added event-related fear and COVID-19 anxiety as new exogenous predictors of the TAM.

\subsection{Limitations and Future Studies}

The current work has numerous limitations. First, it examined TAM in the health information applications context. Future research might examine the TAM in relationship to other technologies. In addition, although TAM can explain technology usage behaviour, future studies need to use UTAUT and other models for an enriching contribution to the literature. Second, event-related fear and COVID-19 anxiety were found to significantly predict Tabaud App intention and Tabaud App usage in the context of consumers' acceptance of health information applications. Hence, the need exists for further tests of these relationships in other contexts such as health professionals, besides the link between social capital and the way of fighting the pandemic. More interesting would be to test how event-related fear and COVID-19 anxiety can predict mHealth applications usage in different organisational and sociodemographic settings in line with the TAM. This research would add to the literature of the TAM model.

Additionally, the study focused on the psychological determinants resulting from COVID-19 using a mobile health app (perspective of psychology or psychiatry). Future research might examine other factors such as lack of trust in the state (government) and its way of dealing with the pandemic.

In addition, the present study was undertaken in a Saudi context, which limits the findings internationally. Future research can overcome this limitation by using large samples from other developing countries or extended to Western countries, such as Canada, New Zealand, the United Kingdom, and the United States. Furthermore, the cross-sectional design does not consider responses at different time intervals. Notably, some constructs (such as usage behaviour) need a period to pass to be measured correctly. This limitation is thought to be a limitation of most TAM-based research. Future studies may take comparative studies or judge the pre-adoption and post-adoption behaviour of mHealth applications. The time factor is worth investigating where some time is needed for conclusive data to emerge and mean something. The issue of generalisability is a widely known limitation in most of the research on technology acceptance. The research posed considerable challenges to access citizens due to the lockdown. Due to the spreading of the pandemic and the strict lockdowns, the study adopted a snowball sample. Lastly, people may be suddenly exposed to risky incidents such as earthquakes, terrorist attacks, and infectious diseases. These events may provide a rich new context to investigate how these events affect information system adoption for users. 
Author Contributions: Conceptualization, A.A. and M.A.; formal analysis, A.A.; investigation, N.A.; methodology, N.A.; project administration, R.M.; resources, M.A.-B. and A.L.; software, A.L.; supervision, M.A.-B.; validation, M.A.; writing—original draft, A.A.; writing—review and editing, R.M. All authors have read and agreed to the published version of the manuscript.

Funding: This research received no external funding.

Data Availability Statement: The data presented in this study are available on request from the corresponding author.

Conflicts of Interest: The authors declare no conflict of interest.

\section{Appendix A}

Table A1. Variables with measurement items factors.

\begin{tabular}{|c|c|c|}
\hline Covide-19 Anxiety & Items & Reference \\
\hline CI1 & $\begin{array}{l}\text { To what extent are you concerned about Covid-19 } \\
\text { pandemic? }\end{array}$ & \multirow{9}{*}{ Wheaton et al. (2012). } \\
\hline $\mathrm{CI} 2$ & $\begin{array}{l}\text { To what extent do you believe that Covid-19 could become a } \\
\text { "pandemic" in the Saudi Arabia? }\end{array}$ & \\
\hline $\mathrm{CI} 3$ & $\begin{array}{l}\text { How likely is it that you could become infected with } \\
\text { Covid- } 19 \text { pandemic? }\end{array}$ & \\
\hline CI4 & $\begin{array}{l}\text { How likely it is that someone you know could become } \\
\text { infected with Covid-19 pandemic? }\end{array}$ & \\
\hline CI5 & $\begin{array}{c}\text { How quickly do you believe contamination from Covid-19 } \\
\text { pandemic is spreading in Saudi Arabia? }\end{array}$ & \\
\hline CI6 & $\begin{array}{l}\text { If you did become infected with Covid-19 pandemic, to } \\
\text { what extent are you concerned that you will be severely ill? }\end{array}$ & \\
\hline $\mathrm{CI} 7$ & $\begin{array}{l}\text { To what extent has the threat of Covid- } 19 \text { pandemic } \\
\text { influenced your decisions to be around people? }\end{array}$ & \\
\hline $\mathrm{CI} 8$ & $\begin{array}{c}\text { To what extent has the threat of Covid-19 pandemic } \\
\text { influenced your travel plans? }\end{array}$ & \\
\hline $\mathrm{CI} 9$ & $\begin{array}{l}\text { To what extent has the threat of Covid-19 pandemic } \\
\text { influenced your use of safety behaviors (e.g., hand } \\
\text { sanitizer)? }\end{array}$ & \\
\hline Event Related Fear & Items & Reference \\
\hline ERF1 & The current Covid-19 pandemic makes me feel afraid" & \multirow{3}{*}{ Boudreaux et al. (2010). } \\
\hline ERF2 & The current Covid-19 pandemic makes me feel anxious" & \\
\hline ERF3 & $\begin{array}{c}\text { "when I think of The current Covid-19 pandemic, I get very } \\
\text { scared about what might happen to me" }\end{array}$ & \\
\hline Tabaud App Usage & Items & Reference \\
\hline TAU1 & $\begin{array}{l}\text { I downloaded the Tabaud App on my device during the } \\
\text { Covid-19 pandemic. }\end{array}$ & \multirow{3}{*}{ Venkatesh et al. (2012). } \\
\hline TAU2 & $\begin{array}{l}\text { Currently using the Tabaud App during the outbreak of the } \\
\text { Corona Virus (Covid-19) pandemic }\end{array}$ & \\
\hline TAU3 & $\begin{array}{l}\text { Use the Tabaud App frequently during the outbreak of the } \\
\text { Corona Virus (Covid-19) pandemic. }\end{array}$ & \\
\hline Perceived Usefulness & Items & Reference \\
\hline PU1 & $\begin{array}{c}\text { Using Tabaud app is useful to protect me from Covid-19 } \\
\text { pandemic. }\end{array}$ & \multirow{4}{*}{$\begin{array}{l}\text { Davis (1989), Taylor and Todd (1995), } \\
\text { Salloum and Al-Emran (2018) }\end{array}$} \\
\hline PU2 & $\begin{array}{c}\text { Using Tabaud app increases my attention about Covid-19 } \\
\text { pandemic. }\end{array}$ & \\
\hline PU3 & $\begin{array}{l}\text { Using Tabaud app helps me reduce the time it takes to } \\
\text { identify infected cases in contact with me }\end{array}$ & \\
\hline PU4 & $\begin{array}{l}\text { The use of the Tabaud app enhances the efficiency of } \\
\text { epidemiological surveillance to isolate people in contact } \\
\text { with infected cases during the Covid-19 pandemic. }\end{array}$ & \\
\hline
\end{tabular}


Table A1. Cont.

\begin{tabular}{|c|c|c|}
\hline Perceived Ease of Use & Items & Reference \\
\hline PEOU1 & \multirow{4}{*}{$\begin{array}{c}\text { I feel that Tabaud App is easy to use. } \\
\text { I feel that Tabaud App is convenient. } \\
\text { Getting the information that I want from the Tabaud App is } \\
\text { easy. } \\
\text { Tabaud App requires no training. }\end{array}$} & \multirow{4}{*}{$\begin{array}{l}\text { Davis (1989), Taylor and Todd (1995), } \\
\text { Salloum and Al-Emran (2018) }\end{array}$} \\
\hline PEOU2 & & \\
\hline PEOU3 & & \\
\hline PEOU4 & & \\
\hline Tabaud App Intention & Items & Reference \\
\hline TAI1 & $\begin{array}{l}\text { I intend to continue using Tabaud App during the Covid-19 } \\
\text { pandemic outbreak. }\end{array}$ & \multirow{3}{*}{ Venkatesh et al. (2012). } \\
\hline TAI2 & $\begin{array}{c}\text { I will always try to use Tabaud App during the Covid-19 } \\
\text { pandemic outbreak. }\end{array}$ & \\
\hline TAI3 & $\begin{array}{l}\text { I plan to continue to use Tabaud App during the Covid-19 } \\
\text { pandemic outbreak. }\end{array}$ & \\
\hline
\end{tabular}

\section{References}

Alam, Mohammad Zahedul, Md Rakibul Hoque, Wang Hu, and Zapan Barua. 2020. Factors influencing the adoption of mHealth services in a developing country: A patient-centric study. International Journal of Information Management 50: 128-43. [CrossRef]

Al-Bsheish, Mohammad, Mu'taman Jarrar, and Amanda Scarbrough. 2021. Public safety compliance model of safety behaviors in the age of the COVID-19 pandemic. INQUIRY: The Journal of Health Care Organization, Provision, and Financing 58: 1-6. [CrossRef]

Al-Dmour, Hani, Amer Salman, Mohammad Abuhashesh, and Rand Al-Dmour. 2020. Influence of social media platforms on public health protection against the COVID-19 pandemic via the mediating effects of public health awareness and behavioral changes: Integrated model. Journal of Medical Internet Research 22: e19996. [CrossRef] [PubMed]

Alkhamees, Abdulmajeed A., Saleh A. Alrashed, Ali A. Alzunaydi, Ahmed S. Almohimeed, and Moath S. Aljohani. 2020. The psychological impact of COVID-19 pandemic on the general population of Saudi Arabia. Comprehensive Psychiatry 102: 152192. [CrossRef] [PubMed]

Al-Okaily, Manaf, Hamza Alqudah, Ali Matar, Abdalwali Lutfi, and Abdallah Taamneh. 2020a. Dataset on the Acceptance of e-learning System among Universities Students' under the COVID-19 Pandemic Conditions. Data in Brief 32: 106176. [CrossRef]

Al-Okaily, Manaf, H. Alqudah, Ali Matar, A. A. Lutfi, and Abdallah Taamneh. 2020b. Impact of COVID-19 pandemic on acceptance of elearning system in Jordan: A case of transforming the traditional education systems. Humanities and Social Sciences Review 6: 840-51. [CrossRef]

Al-Okaily, Manaf, Abdalwali Lutfi, Abdallah Alsaad, Abdallah Taamneh, and Adi Alsyouf. 2020c. The determinants of digital payment systems' acceptance under cultural orientation differences: The case of uncertainty avoidance. Technology in Society 63: 101367. [CrossRef]

Alshira'h, Ahmad Farhan, Moh Alsqour, Abdalwali Lutfi, Adi Alsyouf, and Malek Alshirah. 2020a. A socio-economic model of sales tax compliance. Economies 8: 88. [CrossRef]

Alshira'h, Ahmad Farhan, Hasan Mahmoud Al-Shatnawi, Manaf Al-Okaily, Abdalwali Lutfi, and Malek Hamed Alshirah. 2020b. Do public governance and patriotism matter? Sales tax compliance among small and medium enterprises in developing countries: Jordanian evidence. EuroMed Journal of Business. [CrossRef]

Alshirah, M., Abdalwali Lutfi, A. Alshirah, Mohamed Saad, N. Ibrahim, and F. Mohammed. 2021. Influences of the environmental factors on the intention to adopt cloud-based accounting information system among SMEs in Jordan. Accounting 7: 645-54. [CrossRef]

Al-Syouf, Adi. 2017. Personality, Top Management Support, Continuance Intention to Use Electronic Health Record System among Nurses in Jordan. Ph.D. thesis, Universiti Utara Malaysia, Changlun, Malaysia. unpublished thesis. Available online: http: / / etd.uum.edu.my/6761/ (accessed on 1 September 2021).

Alsyouf, Adi. 2020. Mobile health for covid-19 pandemic surveillance in developing countries: The case of Saudi Arabia. Solid State Technology 63: 2474-85.

Alsyouf, Adi. 2021. Self-efficacy and personal innovativeness influence on nurses beliefs about EHRS usage in Saudi Arabia: Conceptual model. International Journal of Management (IJM) 12: 1049-58. [CrossRef]

Alsyouf, Adi, and Awanis Ku Ishak. 2018. Understanding EHRs continuance intention to use from the perspectives of UTAUT: Practice environment moderating effect and top management support as predictor variables. International Journal of Electronic Healthcare 10: 24-59. [CrossRef]

Asmundson, Gordon, and Steven Taylor. 2020. How health anxiety influences responses to viral outbreaks like COVID-19: What all decision-makers, health authorities, and health care professionals need to know. Journal of Anxiety Disorders 71: 102211. [CrossRef] [PubMed]

Baptista, Gonçalo, and Tiago Oliveira. 2016. A weight and a meta-analysis on mobile banking acceptance research. Computers in Human Behavior 63: 480-89. [CrossRef] 
Binyamin, Sami S., and Bassam Zafar. 2021. Proposing a mobile apps acceptance model for users in the health area: A systematic literature review and meta-analysis. Health Informatics Journal 27: 1460458220976737. [CrossRef] [PubMed]

Boudreaux, Edwin D., Simon Moon, Brigitte M. Baumann, Carlos A. Camargo Jr., P. H. Erin O’Hea, and Douglas M. Ziedonis. 2010. Intentions to quit smoking: Causal attribution, perceived illness severity, and event-related fear during an acute health event. Annals of Behavioral Medicine 40: 350-55. [CrossRef] [PubMed]

Brown, Richard J., Niamh Skelly, and Carolyn A. Chew-Graham. 2020. Online health research and health anxiety: A systematic review and conceptual integration. Clinical Psychology: Science and Practice 27: e12299. [CrossRef]

Byrne, Barbara M. 2010. Structural Equation Modeling with AMOS: Basic Concepts, Applications, and Programming (Multivariate Applications Series). Abingdon: Taylor and Francis Group.

Cao, Wenjun, Ziwei Fang, Guoqiang Hou, Mei Han, Xinrong Xu, Jiaxin Dong, and Jianzhong Zheng. 2020. The psychological impact of the COVID-19 epidemic on college students in China. Psychiatry Research 287: 112934. [CrossRef]

Cheah, Jun Hwa, Ramayah Thurasamy, Mumtaz Ali Memon, Francis Chuah, and Hiram Ting. 2020. Multigroup analysis using SmartPLS: Step-by-step guidelines for business research. Asian Journal of Business Research Volume 10: 1-19.

Chen, Xingyu, Da Tao, and Zhimin Zhou. 2019. Factors affecting reposting behaviour using a mobile phone-based user-generatedcontent online community application among Chinese young adults. Behaviour \& Information Technology 38: 120-31.

Chin, Wynne W. 2010. How to write up and report PLS analyses. In Handbook of Partial Least Squares. Berlin and Heidelberg: Springer, pp. 655-90.

Davis, Fred D. 1989. Perceived usefulness, perceived ease of use, and user acceptance of information technology. MIS Quarterly 13: 319-40. [CrossRef]

Davis, Fred D., Richard P. Bagozzi, and Paul R. Warshaw. 1989. User acceptance of computer technology: A comparison of two theoretical models. Management Science 35: 982-1003. [CrossRef]

Dawson, Carolyn H., Jamie B. Mackrill, and Rebecca Cain. 2017. Assessing user acceptance towards automated and conventional sink use for hand decontamination using the technology acceptance model. Ergonomics 60: 1621-33. [CrossRef]

Deng, Zhaohua, Ziying Hong, Cong Ren, Wei Zhang, and Fei Xiang. 2018. What predicts patients' adoption intention toward mHealth services in China: Empirical study. JMIR mHealth and uHealth 6: e172. [CrossRef] [PubMed]

Dodd, Rachael H., Kevin Dadaczynski, Orkan Okan, Kirsten J. McCaffery, and Kristen Pickles. 2021. Psychological wellbeing and academic experience of University students in Australia during COVID-19. International Journal of Environmental Research and Public Health 18: 866. [CrossRef] [PubMed]

Fan, Fang, Ying Zhang, Yanyun Yang, Lei Mo, and Xianchen Liu. 2011. Symptoms of posttraumatic stress disorder, depression, and anxiety among adolescents following the 2008 Wenchuan earthquake in China. Journal of Traumatic Stress 24: 44-53. [CrossRef] [PubMed]

Fessler, Daniel M., Elizabeth G. Pillsworth, and Thomas J. Flamson. 2004. Angry men and disgusted women: An evolutionary approach to the influence of emotions on risk taking. Organisational Behavior and Human Decision Processes 95: 107-23. [CrossRef]

Finucane, Melissa L., Ali Alhakami, Paul Slovic, and Stephen M. Johnson. 2000. The affect heuristic in judgments of risks and benefits. Journal of Behavioral Decision Making 13: 1-17. [CrossRef]

Fishbein, Martin, and Icek Ajzen. 1977. Belief, attitude, intention, and behavior: An introduction to theory and research. Philosophy and Rhetoric 10: 177-188.

Galasso, Vincenzo, Pons Vincent, Profeta Paola, Becher Michael, Brouard Sylvain, and Foucault Martial. 2020. Gender differences in COVID-19 attitudes and behavior: Panel evidence from eight countries. Proceedings of the National Academy of Sciences 117: 27285-27291. [CrossRef]

Gaygisiz, Ümmügülsüm, Esma Gaygisiz, Türker Özkan, and Timo Lajunen. 2012. Individual differences in behavioral reactions to H1N1 during a later stage of the epidemic. Journal of Infection and Public Health 5: 9-21. [CrossRef]

Gefen, David, Edward E. Rigdon, and Detmar Straub. 2011. Editor's comments: An update and extension to SEM guidelines for administrative and social science research. MIS Quarterly 35: iii-xiv. [CrossRef]

Grogan, Sarah C., Russell Bell, and Mark Conner. 1997. Eating sweet snacks: Gender differences in attitudes and behaviour. Appetite 28: 19-31. [CrossRef] [PubMed]

Hair, Joseph F., William Cormack Black, Barry J. Babin, and Rolph E. Anderson. 2010. Multivariate Data Analysis, 7th ed. Hoboken: Prentice-Hall.

Hair, Joseph F., Christian M. Ringle, and Marko Sarstedt. 2011. PLS-SEM: Indeed a silver bullet. Journal of Marketing Theory and Practice 19: 139-52. [CrossRef]

Hair, Joseph F., Christian M. Ringle, and Marko Sarstedt. 2013. Partial least squares structural equation modeling: Rigorous applications, better results and higher acceptance. Long Range Planning 46: 1-12. [CrossRef]

Hair, Joseph F., Marko Sarstedt, Lucas Hopkins, and Volker G. Kuppelwieser. 2014. Partial least squares structural equation modeling (PLS-SEM): An emerging tool in business research. European Business Review 26: 106-21. [CrossRef]

Henseler, Jörg. 2012. PLS-MGA: A non-parametric approach to partial least squares-based multi-group analysis. In Challenges at the Interface of Data Analysis, Computer Science, and Optimisation. Edited by Wolfgang A. Gaul, Andreas Geyer-Schulz, Lars Schmidt-Thieme and Jonas Kunze. Berlin and Heidelberg: Springer, pp. 495-501. 
Henseler, Jörg, and Georg Fassott. 2010. Testing moderating effects in PLS path models: An illustration of available procedures. In Handbook of Partial Least Squares. Edited by Vincenzo Esposito Vinzi, Wynne W. Chin, Jörg Henseler and Huiwen Wang. Berlin and Heidelberg: Springer, pp. 713-35.

Holmes, Emily A., Rory C. O'Connor, V. Hugh Perry, Irene Tracey, Simon Wessely, Louise Arseneault, Clive Ballard, Helen Christensen, Roxane Cohen Silver, Ian Everall, and et al. 2020. Multidisciplinary research priorities for the COVID-19 pandemic: A call for action for mental health science. The Lancet Psychiatry 7: 547-60. [CrossRef]

Hsu, Hung Hsiou, and Ya Hui Wu. 2017. Investigation of the effects of a nursing information system by using the technology acceptance model. CIN: Computers, Informatics, Nursing 35: 315-22. [CrossRef]

Huang, Yeen, and Ning Zhao. 2020. Generalised anxiety disorder, depressive symptoms and sleep quality during COVID-19 outbreak in China: A web-based cross-sectional survey. Psychiatry Research 288: 112954. [CrossRef]

Hwang, Yujong, Mohanned Al-Arabiat, and Dong Hee Shin. 2016. Understanding technology acceptance in a mandatory environment: A literature review. Information Development 32: 1266-83. [CrossRef]

Jalloh, Mohamed F., Wenshu Li, Rebecca E. Bunnell, Kathleen A. Ethier, Ann O’Leary, Kathy M. Hageman, Paul Sengeh, Mohammad B. Jalloh, Oliver ' Morgan, Sara Hersey, and et al. 2018. Impact of Ebola experiences and risk perceptions on mental health in Sierra Leone, July 2015. BMJ Global Health 3: e000471. [CrossRef]

Johnson, Eric J., and Amos Tversky. 1983. Affect, generalisation, and the perception of risk. Journal of Personality and Social Psychology 45: 20-31. [CrossRef]

Jungmann, Stefanie M., and Michael Witthöft. 2020. Health anxiety, cyberchondria, and coping in the current COVID-19 pandemic: Which factors are related to coronavirus anxiety? Journal of Anxiety Disorders 73: 102239. [CrossRef] [PubMed]

Keil, Mark, Bernard C. Tan, Kwok Kee Wei, Timo Saarinen, Virpi Tuunainen, and Arjen Wassenaar. 2000. A cross-cultural study on escalation of commitment behavior in software projects. MIS Quarterly 24: 299-325. [CrossRef]

Kendler, Kenneth S., Laura M. Thornton, and Carol A. Prescott. 2001. Gender differences in the rates of exposure to stressful life events and sensitivity to their depressogenic effects. American Journal of Psychiatry 158: 587-93. [CrossRef] [PubMed]

Khassawneh, Abd Alwali Lutfi. 2014. The influence of organisational factors on accounting information systems (AIS) effectiveness: A study of Jordanian SMEs. International Journal of Marketing and Technology 4: 240-48.

Kirchmeyer, Catherine. 2002. Change and stability in managers' gender roles. Journal of Applied Psychology 87: 929-39. [CrossRef]

Kissi, Jonathan, Baozhen Dai, Courage S. K. Dogbe, Jonathan Banahene, and Oyeh Ernest. 2020. Predictive factors of physicians' satisfaction with telemedicine services acceptance. Health Informatics Journal 26: 1866-80. [CrossRef]

Konrad, Alison M., J. Edgar Ritchie Jr., Pamela Lieb, and Elizabeth Corrigall. 2000. Sex differences and similarities in job attribute preferences: A meta-analysis. Psychological Bulletin 126: 593-641. [CrossRef]

Krejcie, Robert V., and Daryle W. Morgan. 1970. Determining sample size for research activities. Educational and Psychological Measurement 30: 607-10. [CrossRef]

Lai, Jianbo, Simeng Ma, Ying Wang, Zhongxiang Cai, Jianbo Hu, Ning Wei, Jiang Wu, Hui Du, Tingting Chen, Ruiting Li, and et al. 2020. Factors associated with mental health outcomes among health care workers exposed to coronavirus disease 2019. JAMA Network Open 3: e203976. [CrossRef] [PubMed]

Lau, Joseph T. F., Sian Griffiths, Kai Chow Choi, and Hi Yi Tsui. 2010. Avoidance behaviors and negative psychological responses in the general population in the initial stage of the H1N1 pandemic in Hong Kong. BMC Infectious Diseases 10: 139. [CrossRef]

Lei, Lei, Xiaoming Huang, Shuai Zhang, Jinrong Yang, Lin Yang, and Min Xu. 2020. Comparison of prevalence and associated factors of anxiety and depression among people affected by versus people unaffected by quarantine during the COVID-19 epidemic in southwestern China. Medical Science Monitor: International Medical Journal of Experimental and Clinical Research 26: e924609-1. [CrossRef]

Lerner, Jennifer S., and Dacher Keltner. 2000. Beyond valence: Toward a model of emotion-specific influences on judgement and choice. Cognition and Emotion 14: 473-93. [CrossRef]

Lerner, Jennifer S., Roxana M. Gonzalez, Deborah A. Small, and Baruch Fischhoff. 2003. Effects of fear and anger on perceived risks of terrorism: A national field experiment. Psychological Science 14: 144-50. [CrossRef]

Li, Junde, Qi Ma, Alan HS Chan, and S. S. Man. 2019. Health monitoring through wearable technologies for older adults: Smart wearables acceptance model. Applied Ergonomics 75: 162-69. [CrossRef]

Liu, Nianqi, Fan Zhang, Cun Wei, Yanpu Jia, Zhilei Shang, Luna Sun, and Lili Wu. 2020. Prevalence and predictors of PTSS during COVID-19 outbreak in China hardest-hit areas: Gender differences matter. Psychiatry Research 287: 112921. [CrossRef]

Loewenstein, George F., Elke U. Weber, Christopher K. Hsee, and Ned Welch. 2001. Risk as feelings. Psychological Bulletin 127: 267-86. [CrossRef]

Lutfi, Abdalwali. 2020. Investigating the moderating effect of Environment Uncertainty on the relationship between institutional factors and ERP adoption among Jordanian SMEs. Journal of Open Innovation: Technology, Market, and Complexity 6: 91. [CrossRef]

Lutfi, AbdAlwali, Idris Kamil Md, and Rosli Mohamad. 2016. The influence of technological, organisational and environmental factors on accounting information system usage among Jordanian small and medium-sized enterprises. International Journal of Economics and Financial Issues 6: 240-48.

Lutfi, AbdAlwali, Idris Kamil Md, and Rosli Mohamad. 2017. AIS usage factors and impact among Jordanian SMEs: The moderating effect of environmental uncertainty. Journal of Advanced Research in Business and Management Studies 6: 24-38. 
Lutfi, Abdalwali, Manaf Al-Okaily, Adi Alsyouf, Abdallah Alsaad, and Abdallah Taamneh. 2020. The impact of AIS usage on AIS effectiveness among Jordanian SMEs: A multi-group analysis of the role of firm size. Global Business Review, 0972150920965079. [CrossRef]

Mathieson, Kieran, Eileen Peacock, and Wynne W. Chin. 2001. Extending the technology acceptance model: The influence of perceived user resources. ACM SIGMIS Database: The DATABASE for Advances in Information Systems 32: 86-112. [CrossRef]

Mayes, Jonathan, Andrew White, Matthew Byrne, and Jasper Mogg. 2016. How smartphone technology is changing healthcare in developing countries. The Journal of Global Health at Columbia University 6: 36-38.

McLean, Carmen P., and Emily R. Anderson. 2009. Brave men and timid women? A review of the gender differences in fear and anxiety. Clinical Psychology Review 29: 496-505. [CrossRef]

McLean, Carmen P., Anu Asnaani, Brett T. Litz, and Stefan G. Hofmann. 2011. Gender differences in anxiety disorders: Prevalence, course of illness, comorbidity and burden of illness. Journal of Psychiatric Research 45: 1027-35. [CrossRef] [PubMed]

Ministry of Health. 2020. MOH Apps for Smartphones. Available online: https://www.moh.gov.sa/en/Support/Pages/MobileApp. aspx (accessed on 20 August 2020).

Minton, Henry L., and Frank W. Schneider. 1980. Differential Psychology. Long Grove: Waveland Press.

Moreno, Carmen, Til Wykes, Silvana Galderisi, Merete Nordentoft, Nicolas Crossley, Nev Jones, Mary Cannon, Christoph U Correll, Louise Byrne, Sarah Carr, and et al. 2020. How mental health care should change as a consequence of the COVID-19 pandemic. The Lancet Psychiatry 7: 813-24. [CrossRef]

Ni, Michael Y., Lin Yang, Candi M. C. Leung, Na Li, Xiaoxin I. Yao, Yishan Wang, Gabriel M. Leung, Benjamin J. Cowling, and Qiuyan Liao. 2020. Mental health, risk factors, and social media use during the COVID-19 epidemic and cordon sanitaire among the community and health professionals in Wuhan, China: Cross-sectional survey. JMIR Mental Health 7: e19009. [CrossRef]

Qiu, Jianyin, Bin Shen, Min Zhao, Zhen Wang, Bin Xie, and Yifeng Xu. 2020. A nationwide survey of psychological distress among Chinese people in the COVID-19 epidemic: Implications and policy recommendations. General Psychiatry 33: e100213. [CrossRef]

Rajkumar, Ravi Philip. 2020. COVID-19 and mental health: A review of the existing literature. Asian Journal of Psychiatry 52: 102066. [CrossRef] [PubMed]

Rathnayake, Sarath, Wendy Moyle, Cindy Jones, and Pauline Calleja. 2020. Family carers' needs related to management of functional disability in dementia care and use of mHealth applications in health information seeking: An online survey. Collegian 27: 288-97. [CrossRef]

Rosenbaum, Lisa. 2020. Facing COVID-19 in Italy_Ethics, logistics, and therapeutics on the epidemic's front line. New England Journal of Medicine 382: 1873-75. [CrossRef]

Roy, Deblina, Sarvodaya Tripathy, Sujita Kumar Kar, Nivedita Sharma, Sudhir Kumar Verma, and Vikas Kaushal. 2020. Study of knowledge, attitude, anxiety \& perceived mental healthcare need in Indian population during COVID-19 pandemic. Asian Journal of Psychiatry 51: 102083.

Rzymski, Piotr, Joanna Zeyland, Barbara Poniedziałek, Ilona Małecka, and Jacek Wysocki. 2021. The Perception and Attitudes toward COVID-19 Vaccines: A Cross-Sectional Study in Poland. Vaccines 9: 382. [CrossRef] [PubMed]

Sadowski, Adam, Zbigniew Galar, Robert Walasek, Grzegorz Zimon, and Per Engelseth. 2021. Big data insight on global mobility during the Covid-19 pandemic lockdown. Journal of big Data 8: 1-33. [CrossRef]

Salloum, Said A., and Mostafa Al-Emran. 2018. Factors affecting the adoption of E-payment systems by university students: Extending the TAM with trust. International Journal of Electronic Business 14: 371-390. [CrossRef]

Sarstedt, Marko, Christian M. Ringle, and Joseph F. Hair. 2014. PLS-SEM: Looking back and moving forward. Long Range Planning 47: 132-37. [CrossRef]

Saudi Data and Artificial Intelligence Authority. 2020. Tabaud 2020. Available online: https://tabaud.sdaia.gov.sa/IndexEn (accessed on 20 August 2020).

Sezgin, Emre, Sevgi Özkan-Yildirim, and Soner Yildirim. 2018. Understanding the perception towards using mHealth applications in practice: Physicians' perspective. Information Development 34: 182-200. [CrossRef]

Shi, Qiujie, Danny Dorling, Guangzhong Cao, and Tao Liu. 2020a. Changes in population movement make COVID-19 spread differently from SARS. Social Science \& Medicine 255: 113036.

Shi, Yudong, Juan Wang, Yating Yang, Zhiqiang Wang, Guoqing Wang, Kenji Hashimoto, Kai Zhang, and Huanzhong Liu. 2020b. Knowledge and attitudes of medical staff in Chinese psychiatric hospitals regarding COVID-19. Brain, Behavior, E Immunity-Health 4: 100064.

Slovic, Paul, Melissa L. Finucane, Ellen Peters, and Donald G. MacGregor. 2004. Risk as analysis and risk as feelings: Some thoughts about affect, reason, risk, and rationality. Risk Analysis: An International Journal 24: 311-22. [CrossRef] [PubMed]

Smith, Julia. 2019. Overcoming the 'tyranny of the urgent': Integrating gender into disease outbreak preparedness and response. Gender \& Development 27: 355-369.

Sun, Shufang, Simon B. Goldberg, Danhua Lin, Shan Qiao, and Don Operario. 2021. Psychiatric symptoms, risk, and protective factors among university students in quarantine during the COVID-19 pandemic in China. Globalization and Health 17: 1-14.

Tao, Da, Juan Yuan, Fenglian Shao, Debiao Li, Qi Zhou, and Xingda Qu. 2018. Factors affecting consumer acceptance of an online health information portal among young internet users. CIN: Computers, Informatics, Nursing 36: 530-39. [CrossRef]

Tao, Da, Tieyan Wang, Tieshan Wang, Tingru Zhang, Xiaoyan Zhang, and Xingda Qu. 2020a. A systematic review and meta-analysis of user acceptance of consumer-oriented health information technologies. Computers in Human Behavior 104: 106147. [CrossRef] 
Tao, Da, Fenglian Shao, Hailiang Wang, Mian Yan, and Xingda Qu. 2020b. Integrating usability and social cognitive theories with the technology acceptance model to understand young users' acceptance of a health information portal. Health Informatics Journal 26: 1347-62. [CrossRef] [PubMed]

Tausczik, Yla, Kate Faasse, James W. Pennebaker, and Keith J. Petrie. 2012. Public anxiety and information seeking following the H1N1 outbreak: Blogs, newspaper articles, and Wikipedia visits. Health Communication 27: 179-85. [CrossRef]

Taylor, Shirley, and Peter A. Todd. 1995. Understanding information technology usage: A test of competing models. Information Systems Research 6: 144-76. [CrossRef]

Teng, Ziwei, Zirou Wei, Yan Qiu, Yuxi Tan, Jindong Chen, Hui Tang, Haishan Wu, Renrong Wu, and Jing Huang. 2020. Psychological status and fatigue of frontline staff two months after the COVID-19 pandemic outbreak in China: A cross-sectional study. Journal of Affective Disorders 275: 247-52. [CrossRef]

Tsai, Tsai-Hsuan, Wen-Yen Lin, Yung-Sheng Chang, Po-Cheng Chang, and Ming-Yih Lee. 2020. Technology anxiety and resistance to change behavioral study of a wearable cardiac warming system using an extended TAM for older adults. PLoS ONE 15: e0227270. [CrossRef]

Venkatesh, Viswanath, and Fred D. Davis. 2000. A theoretical extension of the technology acceptance model: Four longitudinal field studies. Management Science 46: 186-204. [CrossRef]

Venkatesh, Viswanath, and Michael G. Morris. 2000. Why don't men ever stop to ask for directions? Gender, social influence, and their role in technology acceptance and usage behavior. MIS Quarterly 24: 115-39. [CrossRef]

Venkatesh, Viswanath, Michael G. Morris, and Phillip L. Ackerman. 2000. A longitudinal field investigation of gender differences in individual technology adoption decision-making processes. Organisational Behavior and Human Decision Processes 83: 33-60. [CrossRef]

Venkatesh, Viswanath, Michael G. Morris, Gordon B. Davis, and Fred D. Davis. 2003. User acceptance of information technology: Toward a unified view. MIS Quarterly 27: 425-78. [CrossRef]

Venkatesh, Viswanath, James Y. L. Thong, Frank K. Y. Chan, Paul Jen-Hwa Hu, and Susan A. Brown. 2011. Extending the two-stage information systems continuance model: Incorporating UTAUT predictors and the role of context. Information Systems Journal 21: 527-55. [CrossRef]

Venkatesh, Viswanath, James Y. L. Thong, and Xin Xu. 2012. Consumer acceptance and use of information technology: Extending the unified theory of acceptance and use of technology. MIS Quarterly 36: 157-78. [CrossRef]

Wang, Cuiyan, Riyu Pan, Xiaoyang Wan, Yilin Tan, Linkang Xu, Cyrus S. Ho, and Roger C. Ho. 2020a. Immediate psychological responses and associated factors during the initial stage of the 2019 coronavirus disease (COVID-19) epidemic among the general population in China. International Journal of Environmental Research and Public Health 17: 1729. [CrossRef] [PubMed]

Wang, Cuiyan, Riyu Pan, Xiaoyang Wan, Yilin Tan, Linkang Xu, Roger S. McIntyre, Faith N. Choo, Bach Trancd, Roger Hoef, Vijay K. Sharmahi, and et al. 2020b. A longitudinal study on the mental health of general population during the COVID-19 epidemic in China. Brain, Behavior, and Immunity 87: 40-48. [CrossRef]

Wheaton, Michael G., Jonathan S. Abramowitz, Noah C. Berman, Laura E. Fabricant, and Bunmi O. Olatunji. 2012. Psychological predictors of anxiety in response to the H1N1 (swine flu) pandemic. Cognitive Therapy and Research 36: 210-18. [CrossRef]

Williams, Paula G. 2004. The psychopathology of self-assessed health: A cognitive approach to health anxiety and hypochondriasis. Cognitive Therapy and Research 28: 629-44. [CrossRef]

Wright, William F., and Gordon H. Bower. 1992. Mood effects on subjective probability assessment. Organisational Behavior and Human Decision Processes 52: 276-91. [CrossRef]

Yang, Chun, James Price Dillard, and Ruobing Li. 2018. Understanding fear of Zika: Personal, interpersonal, and media influences. Risk Analysis 38: 2535-45. [CrossRef] [PubMed]

Yuen, Allan H. K., and Will W. K. Ma. 2002. Gender differences in teacher computer acceptance. Journal of Technology and Teacher Education 10: 365-82.

Zhang, Yingfei, and Zheng Feei Ma. 2020. Impact of the COVID-19 pandemic on mental health and quality of life among local residents in Liaoning Province, China: A cross-sectional study. International Journal of Environmental Research and Public Health 17: 2381. [CrossRef] [PubMed]

Zhang, Xiaofei, Xiaocui Han, Yuanyuan Dang, Fanbo Meng, Xitong Guo, and Jiayue Lin. 2017. User acceptance of mobile health services from users' perspectives: The role of self-efficacy and response-efficacy in technology acceptance. Informatics for Health and Social Care 42: 194-206. [CrossRef] [PubMed]

Zhu, Zhangxiang, Yongmei Liu, Xiaoling Che, and Xiaohong Chen. 2018. Moderating factors influencing adoption of a mobile chronic disease management system in China. Informatics for Health and Social Care 43: 22-41. [CrossRef] 